\title{
Model knowledge sharing pada grup Facebook Backpacker Dunia
}

\author{
Aulia Puspaning Galih \\ Program Studi Perpustakaan dan Ilmu Informasi Universitas Brawijaya \\ Jl. M.T. Haryono No.163, Ketawanggede, Malang, Jawa Timur, Indonesia 65145 \\ E-mail: auliapuspa@ub.ac.id
}

Received: December 2017; Accepted: June 2018; Published: June 2018

\begin{abstract}
Facebook is the largest networking site in the world with a growing number of users. Currently, Facebook has evolved into a site that can be used for information sharing by individuals through their personal accounts in the group called 'Backpacker Dunia', totaling 104,130 members whose hobby is traveling all over the world. This study aimed to identify (1) the relationship between commitment, excitement of helping others, reputation, and the group's appreciation of attitudes towards knowledge sharing, (2) the relationship between attitudes toward knowledge sharing and purpose of knowledge sharing, (3) the appropriate model for knowledge sharing in this study. This knowledge sharing model was adapted from the Theory of Reasoned Action (TRA). The method used in this study was quantitative with an online questionnaire instrument to facilitate the collection of data because the respondents were in cyberspace. SEM-PLS and Smart-PLS 3.0 were used as methods and tools for data analysis and constructing a knowledge sharing model in this study. The number of respondents in the study was 54 people. In the model proposed in the study were 4 hypotheses in the tested coefficient path and one of them was not significant. The study reveals that the relationship between commitment and attitude toward knowledge sharing is not significant, while the relationship between excitement of helping others and attitude towards knowledge sharing; reputation and attitude towards knowledge sharing; attitude toward knowledge sharing and purpose of knowledge sharing are significant.
\end{abstract}

Keywords: Knowledge sharing; Facebook; Traveling; Theory of reasoned action

\begin{abstract}
Abstrak
Facebook adalah situs jejaring terbesar di dunia yang berkembang jumlah penggunanya. Facebook yang kini berkembang menjadi situs yang dapat digunakan untuk penyebaran informasi (knowledge sharing) oleh individu melalui akun pribadinya di grup, bernama Backpacker Dunia, berjumlah 104.130 anggota yang memiliki hobi traveling ke seluruh dunia. Penelitian ini bertujuan untuk mengetahui (1) hubungan antara komitmen, kegembiraan membantu orang lain, reputasi, dan penghargaan dari grup terhadap sikap terhadap knowledge sharing, (2) hubungan antara sikap terhadap knowledge sharing dan tujuan melakukan knowledge sharing, (3) model yang sesuai untuk knowledge sharing pada penelitian ini. Model knowledge sharing ini diadaptasi dari Theory of Reasoned Action (TRA). Metode yang digunakan dalam penelitian ini adalah kuantitatif dengan instrumen kuesioner daring untuk mempermudah pengumpulan data karena responden berada di dunia maya.SEM-PLS dan Smart-PLS 3.0 digunakan sebagai metode dan alat untuk analisis data dan pembuatan model knowledge sharing dalam penelitian ini. Jumlah responden dalam penelitian adalah 54 orang. Dalam model yang diajukan dalam penelitian terdapat 4 hipotesis dalam path coefisien yang diuji dan salah satunya tidak signifikan. Dari penelitian diketahui bahwa hubungan antara komitmen dan sikap terhadap knowledge sharing tidak signifikan, sedangkan hubungan antara kegembiraan membantu orang lain dan sikap terhadap knowledge sharing; reputasi dan sikap terhadap knowledge sharing; sikap terhadap knowledge sharingdan tujuan melakukan knowledge sharing adalah signifikan.
\end{abstract}

Kata Kunci: Knowledge sharing; Facebook; Traveling; Theory of reasoned action 


\section{PENDAHULUAN}

Facebook adalah situs jejaring sosial terbesar di dunia yang masih mendominasi dunia maya hingga saat ini. Pengguna aktif bulanan Facebook pada akhir tahun 2016 sejumlah hampir dua miliar, tepatnya 1,86 miliar (Bohang, 2017), dan terus bertambah dari waktu ke waktu. Pengguna Facebook di Indonesia sendiri pada pertengahan tahun 2016 telah mencapai angka 88.000.000 akun dari akhir tahun 2015 yang masih 82.000.000 akun (Yusuf, 2016). Dalam waktu hanya enam bulan, pengguna Facebook di Indonesia bertambah hingga 6.000 .000 akun. Tak ayal, hal ini menjadikan Indonesia dalam peringkat empat pengguna Facebook terbesar di dunia, mencapai sekitar 111.000.000 akun pada April 2017 (Reza, 2017).

Dengan bertambah jumlah pengguna, Facebook yang dulu digunakan untuk menemukan teman, sekarang berkembang menjadi tempat berbisnis dan penyebaran informasi yang sangat cepat. Dengan fitur suka, berbagi dan komentar, suatu informasi dapat menjadi viral dengan begitu mudah dan cepatnya. Selain itu, Facebook menjadi tempat berkumpulnya orang-orang yang memiliki persamaan sudut pandang, aktifitas, dan hobi. Pengguna Facebook membentuk komunitas sendiri dan membuat grup yang berisi orang-orang yang memiliki kesamaan dan berbagi informasi yang bermanfaat bagi kepentingan mereka.

Berbagi informasi itulah yang disebut knowledge sharing. Knowledge sharing adalah proses mentransfer dan mendiseminasikan pengetahuan secara sukarela dari satu orang keorang lain atau grup dalam sebuah organisasi. Knowledge sharing secara virtual berkembang dengan pesat dalam beberapa tahun terakhir.
Bukan hanya organisasi atau perusahaan saja yang melakukan hal tersebut tetapi juga individu yang merasa bahwa pengetahuan yang dimilikinya berguna dan bermanfaat bagi orang lain. Pengetahuan tacit lebih banyak dibagikan dalam grup Facebook, terutama dalam grup traveling karena pengalaman yang dimiliki setiap orang berbeda meskipun mereka mengunjungi lokasi yang sama. Dalam knowledge sharing, dibutuhkan proses transformasi yang berlaku secara individu dari pengetahuan tacit menjadi pengetahuan eksplisit. Di mana pengetahuan tacit adalah pengetahuan yang dimiliki oleh individu yang belum dibagikan kepada orang lain (Fauziyah, Damayani, \& Rohman, 2014; Saepudin, Rusmana, \& Budiono, 2016). Apabila pengetahuan tersebut telah dibagikan kepada pihak lain, maka pengetahuan tersebut adalah pengetahuan eksplisit. Dalam grup Facebook Backpacker Dunia, anggota yang tergabung di dalamnya membagikan informasi mengenai tempat yang mereka kunjungi, mengenai masalah imigrasi, visa, orang-orang, dan budaya di lokasi yang telah mereka kunjungi. Dengan ratusan ribu anggota pada grup tersebut, traffic unggahan informasi dan komentar terjadi dengan cepat dan melimpah.

Tujuan penelitian ini adalah mengidentifikasi apakah ada hubungan antara komitmen, kegembiraan membantu orang lain, reputasi, dan penghargaan dari grup terhadap sikap knowledge sharing, serta mengidentifikasi hubungan antara sikap terhadap knowledge sharing dan tujuan melakukan knowledge sharing. Tujuan berikutnya adalah membuat model yang sesuai dengan pola knowledge sharing pada grup Facebook Backpacker Dunia.

Sesuai latar belakang dan tujuan penelitian yang telah dipaparkan sebe- 
lumnya, maka masalah yang dapat dirumuskan diantaranya, pertama, apakah ada hubungan antara komitmen, kegembiraan membantu orang lain, reputasi, dan penghargaan dari grup mengenai sikap terhadap knowledge sharing. Kedua, apakah ada hubungan antara sikap terhadap knowledge sharing dan tujuan melakukan knowledge sharing. Ketiga, bagaimanakah model yang sesuai untuk knowledge sharing pada grup Facebook Backpacker Dunia?.

Untuk menjawab rumusan masalah yang telah disebutkan sebelumnya, maka diperlukan kerangka teori dan konsep untuk melakukan penelitian ini. Konsep dan teori yang digunakan adalah tentang knowledge sharing, Theory of Reasoned Action (TRA) dan pengembangan model TRA untuk knowledge sharing.

Pengetahuan terletak pada individu dan diciptakan oleh individu. Pengetahuan (knowledge) memiliki peran yang sangat penting dalam kehidupan sehari-hari, baik untuk kebutuhan individu maupun kebutuhan organisasi. Pengetahuan yang dimiliki seseorang dapat disebarkan dengan berbagai cara dan berbagai media, penyebaran pengetahuan inilah yang disebut knowledge sharing. Knowledge sharing bertujuan untuk mengoptimalkan dan mendorong munculnya pengetahuan baru sebagai hasil pembelajaran dan kombinasi dari berbagai pengetahuan yang berbedabeda. Manfaat dari knowledge sharing antara lain, (1) menciptakan kesempatan yang sama bagi anggota organisasi untuk mengakses pengetahuan dan mempelajarinya, (2) menciptakan kecepatan belajar dan mengurangi waktu yang dibutuhkan untuk memperoleh atau mempelajari pengetahuan baru, (3) mempercepat penyelesaian tugas dan pemecahan masalah, (4) menyelesaikan masalah dengan memanfaatkan metode yang sudah terbukti efektif di unit atau di tempat lain sehingga mencegah masalah yang sama terulang kembali, dan (5) menyediakan bahan dasar bagi inovasi berupa pengetahuan yang bervariasi dan multiperspektif (Lumbantobing, 2011).

Pengetahuan yang dimiliki manusia berpengaruh pada perilaku mereka dalam menghadapi sesuatu. Theory of Reasoned Action (TRA), yang menjelaskan mengenai perilaku seseorang berdasarkan tujuan mereka. Fishbein (1975) dalam Fishbein \& Ajzen (2015) mengatakan bahwa TRA adalah teori model yang mengkaji mengenai perilaku manusia.

TRA diadaptasi dalam penelitian ini untuk mengidentifikasi kunci knowledge sharing. TRA mempertimbangkan tingkah laku individu tergantung pada tujuan mereka untuk melakukan suatu hal. TRA secara luas telah digunakan dalam berbagai macam, termasuk knowledge management, kesehatan, psikologi sosial dan adopsi teknologi informasi.

Tsai, Chen, and Chien (2012) melakukan penelitian mengenai psikologi sosial mengenai knowledge sharing yang berhubungan dengan tujuan individu. TRA ini sesuai untuk memprediksi berbagai macam tujuan tingkah laku dan tingkah laku itu sendiri. Meskipun terdapat penelitian yang membahas mengenai model motivasi pada tingkah laku yang berkenaan dengan pengetahuan, tetapi masih sedikit penelitian yang membahas mengenai kunci utama dari tingkah laku knowledge sharing (Ma \& Chan, 2014). Dalam rujukan tersebut membahas knowledge sharing di dunia pendidikan, di mana sasarannya adalah murid SMA yang akan kuliah. Penelitian 
ini mengukur hubungan dan pengaruh knowledge sharing di dunia maya.

Dalam penelitian ini, sebuah model penelitian (lihat Gambar 1) diajukan untuk membahas faktor yang berkaitan dengan motivasi intrinsik (komitmen, kegembiraan membantu orang lain), dan motivasi ekstrinsik (reputasi, penghargaan dari grup) untuk mengidentifikasi peranan motivasi dalam menjelaskan tingkah laku knowledge sharing pada grup Facebook Backpacker Dunia. Penelitian ini menguji komitmen, kegembiraan membantu orang lain, reputasi, dan penghargaan dari grup terhadap sikap knowledge sharing yang akan mempengaruhi tujuan knowledge sharing yang dilakukan oleh anggota grup.

Komitmen adalah bentuk tanggung jawab seseorang untuk membantu dan melakukan knowledge sharing melalui kolaborasi informasi yang rutin dengan orang lain dalam sebuah organisasi. Perasaan memiliki komitmen dan tanggung jawab memperhatikan aspek ketergantungan emosional, identitas dan koneksi dari individu tersebut dalam sebuah organisasi. Keberlanjutan komitmen tersebut adalah tergantung pada keinginannya untuk tetap bertahan dalam organisasi tersebut atau tidak, sedangkan komitmen normatif adalah tanggung jawab dari seseorang untuk terus bertahan dalam organisasi tersebut (Scheible \& Bastos, 2013). Dalam penelitian ini, organisasi tersebut diubah menjadi grup Facebook Backpacker Dunia. Komitmen memiliki efek langsung terhadap hasil pekerjaan dan altruism (Neininger, LehmannWillenbrock, Kauffeld, \& Henschel, 2010), karena setiap anggota mendapatkan pengalaman yang berharga dan memiliki tujuan yang sama sehingga mereka akan terus berkontribusi terhadap organisas- inya. Komitmen dikenal sebagai simbol kekuatan yang signifikan secara kuat dan positif dengan sikap knowledge sharing (Chen \& Cheng, 2012). Oleh karena itu, komitmen memiliki hubungan yang positif dengan knowledge sharing (Abili, Thani, Mokhtarian, \& Rashidi, 2011). Berdasarkan hasil penelitian mereka, komitmen berperan sebagai salah satu faktor kesuksesan organisasi yang berhubungan dengan knowledge sharing.

Kegembiraan membantu orang lain berasal dari persepsi altruisme (Chang \& Chuang, 2011), yang mana termasuk prinsip dan bentuk dari ketidakegoisan seseorang yang mengarah pada kegembiraan intrinsik dengan melakukan knowledge sharing. Pendapat ini didukung oleh Dinther, Dochy, and Segers (2011) yang menyatakan bahwa kegembiraan membantu orang lain dalam mendorong interaksi antar individu untuk saling berbagi informasi dari informasi yang mereka miliki.

Reputasi ternyata mempengaruhi efektivitas knowledge sharing (Abzari, Barzaki, \& Abbasi, 2011). Hubungan yang diteliti dalam rujukan tersebut, tepatnya mengukur hubungan antara reputasi dengan sikap; reputasi dengan tujuan melakukan knowledge sharing. Hubungan kedua hipotesis tersebut signifikan dan menghasilkan kesimpulan bahwa dengan melakukan knowledge sharing maka reputasi responden akan naik. Milne (2007) membagi reputasi menjadi dua kategori yang dapat mempengaruhi knowledge sharing, yang pertama adalah reputasi secara umum; sedangkan yang kedua adalah reputasi spesifik. Reputasi umum merujuk pada kemampuan seseorang secara keseluruhan, dan reputasi spesifik berhubungan dengan kemampuan seseorang untuk memenuhi harapan ter- 
tentu dalam situasi tertentu. Hal ini didukung oleh Prescott and Louis (2010), yang menyatakan bahwa ada hubungan yang positif antara reputasi dan knowledge sharing. Mereka menyatakan bahwa reputasi berpengaruh terhadap proses knowledge sharing yang terjadi dalam organisasi, misalnya siapa yang membutuhkan informasi dan siapa yang akan memberikan informasi, tetapi jangka waktu antar individu berinteraksi tidak mempengaruhi proses berbagi pengetahuan yang mereka lakukan.

Motivasi intrinsik dan motivasi ekstrinsik dapat mempengaruhi sikap terhadap upaya knowledge sharing secara langsung (Jeon, Kim, \& Koh, 2011). Sikap untuk berbagi pengetahuan dan informasi adalah perilaku individu yang positif, demikian juga dengan keinginan individu untuk berbagi informasi dan pengetahuan dengan orang lain secara terbuka dan sukarela. Sikap dipengaruhi oleh persepsi dan tujuan seseorang. Jika seseorang percaya bahwa knowledge sharing adalah hal yang penting dan dibutuhkan, maka mereka akan membagikan pengetahuan yang mereka miliki secara berkala disituasi tertentu. Bagaimanapun, jika seseorang percaya bahwa knowledge sharing adalah hal yang tidak penting, maka mereka cenderung untuk tidak membagikan informasi yang mereka miliki kepada orang lain.

Seperti telah dijelaskan pada tinjauan literatur sebelumnya, maka dapat dibuat model knowledge sharing berdasarkan model Tan and Ramayah (2014) dengan beberapa penyesuaian oleh peneliti untuk penelitian ini, bahwa tujuan melakukan knowledge sharing, memiliki sikap komitmen dalam melakukannya, kegembiraan membantu orang lain atau anggota dan reputasi.

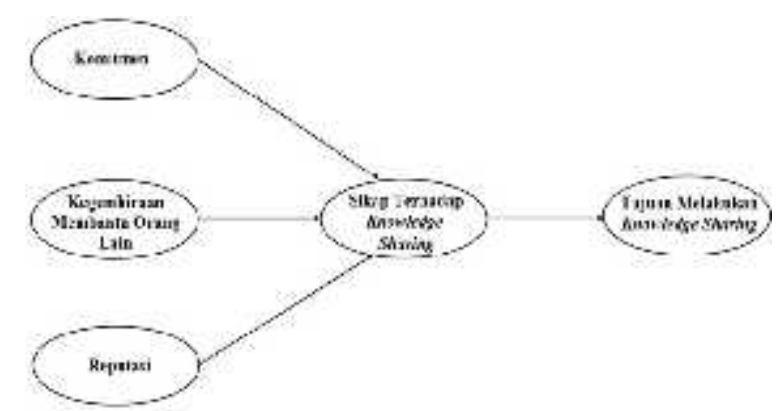

Gambar 1. Model knowledge sharing

Sumber: Tan \& Ramayah (2014)

\section{METODE PENELITIAN}

Penelitian ini menggunakan pendekatan kuantitatif karena dianggap lebih tepat untuk mengkonfirmasi kebenaran hipotesis yang diajukan. Peneliti akan menguji sebuah model dengan merinci hipotesis secara spesifik. Data primer akan dikumpulkan dengan bantuan instrumen khusus berupa kuesioner dengan teknik online survei. Kuesioner akan menggunakan 7-poin skala Likert untuk pertanyaan yang akan digunakan untuk menguji model, jenis pertanyaan tertutup lebih sesuai untuk jenis penelitian ini agar responden lebih fokus dalam menjawab kuesioner.

Fokus penelitian adalah obyek yang paling menarik dan paling bermanfaat untuk diteliti oleh peneliti. Fokus penelitian ini adalah mengidentifikasi adanya hubungan antar variabel dalam model yang diajukan dalam penelitian sehingga dapat diketahui model knowledge sharing pada pengguna Facebook (grup traveling Backpacker Dunia). Fokus penelitian secara spesifik diantaranya, pertama, mengidentifikasi apakah ada hubungan antara komitmen, kegembiraan membantu orang lain, reputasi, dan penghargaan dari grup terhadap sikap terhadap knowledge sharing, serta mengidentifikasi hubungan antara sikap terhadap knowledge sharing dan tujuan melakukan knowledge sharing. Kedua, 
membuat model yang sesuai dengan pola knowledge sharing pada grup FacebookBackpacker Dunia. Dengan fokus penelitian seperti di atas, maka ada 4 hipotesis yang diuji.

H1 Komitmen memiliki hubungan yang positif dengan sikap terhadap knowledge sharing

$\mathrm{H} 2$ Kegembiraan membantu orang lain memiliki hubungan yang positif dengan sikap terhadap knowledge sharing

H3 Reputasi memiliki hubungan yang positif dengan sikap terhadap knowledge sharing

H4 Sikap terhadap knowledge sharing memiliki hubungan yang positif terhadap knowledge sharing

Facebook adalah salah satu situs jejaring sosial terbesar di dunia sehingga banyak peneliti membahas Facebook dan masih layak diteliti hingga saat ini. Situs jejaring sosial Facebook menjadi situs pada penelitian ini, tepatnya grup Facebook Backpacker Dunia. Grup Facebook Backpacker Dunia (dapat diakses di https://www.facebook.com/groups/128 092889677/) dipilih menjadi obyek penelitian ini karena grup ini adalah grup traveling terbesar di Indonesia (Umaedah, 2015), dengan jumlah anggota 104.130 pengguna Facebook dan dengan traffic posting dan komentar yang cukup tinggi.

Sumber data dalam penelitian ada berbagai macam, tergantung pada jenis penelitian itu sendiri, apakah penelitian kuantitatif ataukah kualitatif. Penelitian ini adalah penelitian kuantitatif sehingga data yang akan digunakan sebagai data primer adalah data kuesioner dari responden. Pertama, melalui survey. Kuesioner adalah instrumen dalam metode survei. Dalam penelitian ini, kuesioner dibuat dengan jenis pertanyaan terbuka dan tertutup menggunakan 7poin skala Likert. Kuesioner online lebih sesuai digunakan karena lokasi penelitian ini yang berada di dunia maya, Facebook. Kedua, melalui observasi. Selain survei, observasi perlu dilakukan untuk mendapatkan data yang lebih lengkap dan memantau kesesuaian jawaban pada kuesioner dan pada grup Facebook Backpacker Dunia. Observasi dilakukan dengan aktif membuka dan melihat grup tersebut.

Jenis data dalam penelitian ini adalah data primer dari responden penelitian. Teknik pengumpulan data yang digunakan adalah survei menggunakan instrumen kuesioner. Target penelitian ini adalah pengguna Facebook yang tergabung dalam grup Backpacker Dunia.

Penentuan jumlah sampel dalam penelitian ini menggunakan rumus Roscoe (1975) dalam Zacoeb (2009) untuk pengambilan sampel dengan jumlah populasi tidak diketahui, di mana dinyatakan bahwa pada penelitian multivariat ukuran sampel harus beberapa kali lebih besar (10 kali) dari jumlah variabel yang akan dianalisis. Penelitian ini terdiri dari 5 (lima) variabel sehingga jumlah sampel dalam penelitian ini ditetapkan sebanyak 10 × 5 yaitu 50 orang responden. Jumlah tersebut adalah jumlah minimal, tetapi jumlah responden tidak boleh melebihi 250 orang karena penelitian ini menggunakan SEM-PLS (Sholihin \& Ratmono, 2013). Jumlah responden untuk penelitian ini sendiri adalah 55 orang, tetapi hanya 54 jawaban yang valid.

Lebih lanjut, populasi dalam penelitian ini dinilai memiliki tingkat homogenitas yang cukup seragam 
sehingga jumlah sampel penelitian yang diambil dapat kecil. Singarimbun \& Effendi (2008) menyebutkan adanya derajat keseragaman populasi yang harus dipertimbangkan dalam menentukan jumlah sampel penelitian, di mana makin seragam populasi itu, makin kecil sampel yang dapat diambil dan sebaliknya.

Sampel dalam penelitian ini menggunakan jenis sampel nonprobabilitas. Teknik sampel nonprobabilitas yang akan digunakan dalam penelitian ini adalah sampel purposif. Teknik pengambilan sampel ini dilakukan agar hasil yang didapatkan dapat lebih akurat karena penelitian ini membutuhkan pandangan yang obyektif dari responden penelitian. Kriteria sampel yang dapat ditunjuk sebagai sampel adalah individu yang memenuhi syarat sampel penelitian diantaranya, (1) tergabung dalam grup Facebook Backpacker Dunia, dan (2) aktif mengunggah informasi atau berkomentar dalam grup traveling Facebook Backpacker Dunia.

Instrumen yang digunakan dalam penelitian ini adalah kuesioner dengan 7poin skala Likert, dimulai dari sangat tidak setuju (1) hingga sangat setuju (7), disertai pertanyaan tertutup dan terbuka untuk mengetahui identitas responden. Penelitian ini terdiri dari lima (5) variabel dan diukur menggunakan 11 buah indikator seperti yang ditampilkan pada tabel 1.

Dalam tabel 1, pendekatan Structural Equation Model (SEM) digunakan untuk mengukur hubungan antara eksternal variabel komitmen dengan sikap terhadap knowledge sharing, kegembiraan membantu orang lain dengan sikap terhadap knowledge sharing, reputasi dengan sikap terhadap knowledge sharing, penghargaan dari grup dengan sikap ter- hadap knowledge sharing, serta internal variabel sikap terhadap knowledge sharing dengan tujuan melakukan knowledge sharing. Metode ini digunakan sebagai uji struktural dan mengukur hubungan antar variabel dalam SEM sehingga akan didapatkan hasil analisis lengkap mengenai hubungan antar variabel dalam model.

SEM merupakan metode uji statistik yang digunakan untuk membangun dan menguji model statistik dalam bentuk model sebab akibat. SEM sebenarnya merupakan teknik hibridayang meliputi aspek-aspek penegasan (confirmatory) dari analisis faktor, analisis jalur danregresi. Analisis SEM akan dilakukan dengan software PLS 3.0.

Konsep dimensi tunggal (undimensional) didapatkan saat item yang diukur memiliki loading factor diatas 0.6 untuk item yang stabil dan harus diatas 0.5 untuk item yang baru dikembangkan (Awang, 2011). Selain itu, semua hasil loading factor harus bernilai positif. Apabila ternyata syarat undimensional tidak dapat terpenuhi, maka harus ada item yang dihapus. Item yang dihapus adalah item yang memiliki loading factor yang rendah. Tetapi penghapusan item tidak boleh melebihi dari 20\% total item dalam model secara keseluruhan (Awang, 2011). Dengan adanya 2 loading factor yang di bawah 0.6 pada variabel tujuan melakukan knowledge sharing (TKS), maka kedua item tersebut dihapus. Penghapusan item telah sesuai dengan pendapat yang tidak melebihi $20 \%$ dari total item. Setelah kedua item yang loading factornya dibawah 0.6 dihapus, maka terjadi perubahan hasil seperti yang dapat dilihat pada tabel 2. 
Validitas data diukur untuk menentukan bahwa konstruk penelitian mewakili dan menggambarkan populasi yang ada. Validitas konstruk menentukan adanya kecenderungan hubungan yang erat antara pengukuran konstruk yang sama (convergent validity) dan hubungan yang rendah antara pengukuran konstruk yang dikehendaki (discriminant validity) Straub (1989) dalam Soto-Acosta and Merono-Cerdan (2008), menyatakan bahwa ada tiga jenis validitas yang harus dipenuhi, yaitu convergent validity, validitas konstruk, dan discriminant validity.

Di tabel 3, convergent validity didapatkan dari penghitungan Average Variance Extracted (AVE) untuk setiap konstruk. Nilai dari AVE haruslah lebih dari 0.5 (Hair, Ringle, \& Sarstedt, 2011).

Tabel 3

Nilai average variance extracted (AVE)

\begin{tabular}{ll}
\hline Variabel & Nilai AVE \\
\hline Komitmen & 0.556 \\
$\begin{array}{l}\text { Kegembiraan membantu } \\
\text { orang lain }\end{array}$ & 0.725 \\
$\begin{array}{l}\text { Reputasi } \\
\text { Sikap terhadap knowledge } \\
\text { sharing }\end{array}$ & 0.643 \\
Tujuan melakukan & 0.728 \\
knowledge sharing & 0.664 \\
\hline
\end{tabular}

Sumber: Hasil penelitian, 2017

Sedangkan dalam tabel 4, validitas konstruk didapatkan melalui fitness index terpenuhi. Fitness index mengindikasikan kestabilan item untuk mengukur konstruk laten pada model. Discriminant validity mengindikasikan bahwa konstruk yang diukur bebas dari item berulang (redundant items). Discriminant validity berfungsi mengukur ketepatan model reflektif dengan cara melihat cross loading factor untuk melihat nilai konstruk. Nilai indikatior tiap konstruk harus lebih tinggi dibandingkan nilai korelasi indikator lain.
Tabel 4

Nilai discriminant validity

\begin{tabular}{llllll}
\hline & KG & KO & RE & SKS & TKS \\
\hline KG & 0.851 & & & & \\
KO & 0.640 & 0.746 & & & \\
RE & 0.225 & 0.382 & 0.802 & & \\
SKS & 0.839 & 0.662 & 0.489 & 0.852 & \\
TKS & 0.652 & 0.362 & 0.044 & 0.621 & 0.851 \\
\hline
\end{tabular}

Sumber: Hasil penelitian, 2017

Konsistensi data diukur dengan tiga cara pengukuran, yaitu Cronbach's alpha, composite reliability dan AVE. Di tabel 5.

Tabel 5

Nilai Cronbach's alpha

\begin{tabular}{ll}
\hline Variabel & Nilai Cronbach's alpha \\
\hline Komitmen & 0.806 \\
Kegembiraan & 0.871 \\
membantu orang & \\
lain & \\
Reputasi & 0.842 \\
$\begin{array}{l}\text { Sikap terhadap } \\
\text { knowledge sharing }\end{array}$ & 0.876 \\
$\begin{array}{l}\text { Tujuan } \\
\text { melakukan }\end{array}$ & 0.842 \\
knowledge sharing & \\
\hline Sumber: Hasil penelitian, 2017
\end{tabular}

Berdasarkan hal ini, realibilitas konstruk ditunjukkan dengan nilai Cronbach'a alpha. Nilai Cronbach's alpha harus lebih besar dari 0.5 atau 0.7. Nilai AVE untuk setiap konstruk harus lebih dari 0.5. Syarat-syarat itu harus dipenuhi oleh setiap konstruk, yang mana berarti bahwa konstruk yang digunakan dalam penelitian menunjukkan convergent validity (Hair et al., 2011).

\section{HASIL DAN PEMBAHASAN}

Pada bagian ini dijelaskan mengenai hasil dan analisis data yang didapatkan dari hasil penelitian. Jumlah responden yang valid adalah 54 orang. Dari jumlah responden tersebut dapat 
diketahui jenis kelamin responden, usia responden, domisili responden, dan lama bergabung responden dalam grup traveling Facebook Backpacker Dunia.

Dari penelitian didapatkan data bahwa dari 54 responden, 22 orang berjenis kelamin laki-laki atau sebanyak $41 \%$, sedangkan 32 orang atau sebanyak 59\% adalah responden berjenis kelamin perempuan.

Hasil data penelitian juga menjelaskan mengenai usia responden yang dibagi menjadi lima kelompok usia. Kelompok usia 21-25 berjumlah 8 responden, atau sebanyak 15\%. Kelompok usia 2630 tahun berjumlah 11 orang (20\%). Kelompok usia 31-35 berjumlah 19 orang, atau sebanyak $35 \%$, sedangkan kelompok usia $>35$ tahun berjumlah 16 responden, atau $30 \%$. Jumlah responden paling banyak adalah kelompok usia 31-35 tahun sebanyak 35\% atau 19 orang, sedangkan jumlah responden paling sedikit adalah kelompok usia 16-20 tahun yang berjumlah $0 \%$.

Selanjutnya adalah data mengenai domisili responden. Terdapat 6 (enam) lokasi yang peneliti tuliskan dalam kuesioner, yaitu, Jawa, Sumatra, Kalimantan, Sulawesi, Papua, dan lainnya. Pilihan lainnya adalah jawaban terbuka bagi responden sehingga apabila responden tidak berdomisili pada 5 (lima) pulau yang disebutkan, maka responden harus mengisi lokasi yang sesuai dengan domisili mereka. Sebanyak 36 orang atau $67 \%$ dari responden berdomisili di Pulau Jawa, 6 orang atau $11 \%$ tinggal di Pulau Sumatra, 3 orang lainnya berdomisili di Sulawesi, sedangkan tidak ada responden yang berdomisili di Pulau Kalimantan dan Papua. Terdapat 9 orang atau $17 \%$ responden memilih lokasi lainnya. Pada 9 orang tersebut tinggal di luar negeri, 2 orang berdomisili di Turki, 3 orang berdomisili di Taiwan, 3 orang berdomisili di Malaysia dan 1 orang tinggal di Amerika Serikat.

Hasil data selanjutnya menjelaskan informasi mengenai lama bergabung responden dengan grup Facebook Backpacker Dunia. Jawaban dibagi menjadi lima pilihan, yaitu <6 bulan, 6-11 bulan, 12-17 bulan, $18-23$ bulan dan $>24$ bulan. Tidak ada responden yang bergabung dalam grup travelin Backpacker Dunia selama kurang dari satu tahun atau 12 bulan sehingga pilihan jawaban $<6$ bulan dan 6-11 bulan adalah $0 \%$. Responden minimal telah bergabung selama 12-17 bulan, yaitu sebanyak 9 orang atau $17 \%$, sedangkan masa bergabung antara 18-23 bulan berjumlah 11 orang atau 20\%. Jumlah responden yang bergabung dalam grup $\mathrm{Fa}$ cebook Backpacker Dunia paling banyak adalah 34 orang atau 63\% dengan waktu lama bergabung lebih dari 24 bulan atau 2 tahun.

Pendekatan Structural Equation Modeling (SEM) digunakan untuk mengukur hubungan antara komitmen, kegembiraan membantu orang lain dan reputasi dengan sikap terhadap knowledge sharing, begitu juga dengan hubungan antara sikap terhadap knowledge sharing dengan tujuan melakukan knowledge sharing. PLS tidak mengukur goodness-of-fit secara keseluruhan, sehingga validitas model ditentukan dengan menghitung korelasi dan $\mathrm{R}^{2}$. Boothstrapping digunakan untuk menghitung signifikansi pada SEM-PLS (Henseler, Ringle, \& Sinkovics, 2009) dengan menggunakan t-test (Hair et al., 2011). Melalui Structural Equation Modeling, dapat terlihat indikator sikap dan hubungan sikap dengan tujuan knowledge sharing. 


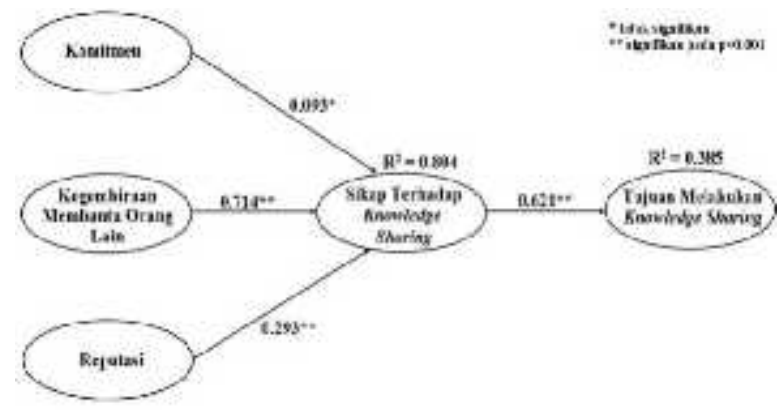

Gambar 2. Hasil model knowledge sharing Sumber: Olahan penulis, 2017

Nilai koefisien dari hubungan komitmen dengan sikap terhadap knowledge sharing adalah 0.093 dengan nilai t-test 1.041 sehingga hasilnya adalah tidak signifikan. Hal ini berarti tidak ada hubungan antara komitmen dengan sikap terhadap knowledge sharing. Komitmen yang ada di dalam grup Backpacker Dunia tidak berhubungan dengan sikap terhadap knowledge sharing karena para anggotanya tidak merasa memiliki kewajiban bahwa mereka harus membagi informasi yang mereka miliki dengan anggota yang lain karena tindakan yang mereka lakukan bersifat sukarela.

Hubungan antara komitmen dengan sikap terhadap knowledge sharing tidak signifikan sehingga hasil penelitian ini bertentangan dengan hasil penelitian sebelumnya. Abili, Thani, Mokhtarian, and Rashidi (2011) menyatakan bahwa komitmen adalah salah satu faktor penting untuk melakukan knowledge sharing yang dilakukan di dalam sebuah organisasi. Dalam penelitian ini, komunitas traveling yang ada pada Facebookyang bernama Backpacker Dunia.

Hubungan antar variabel yang lain (kegembiraan membantu orang lain $\rightarrow$ sikap terhadap knowledge sharing, reputasi $\rightarrow$ sikap terhadap knowledge sharing, sikap terhadap knowledge sharing $\rightarrow$ tujuan melakukan knowledge sharing) adalah signifikan pada $\mathrm{p}$-value $<0.001$.
Hubungan kegembiraan membantu orang lain dan sikap terhadap knowledge sharing memiliki nilai koefisien 0.714 dengan nilai t-test 9.288. Hal ini menunjukkan adanya hubungan yang kuat antara altruisme dengan sikap terhadap knowledge sharing. Para anggota grup Backpacker Dunia senang membagikan informasi yang mereka miliki, terutama pengalaman mereka bepergian keluar negeri yang sekiranya berharga bagi mereka dan bagi orang lain karena pengalaman setiap anggota berbeda. Informasi yang mereka bagikan juga berupa tips dan trik dalam melakukan perjalanan. Pengetahuan mereka akan melakukan perjalanan harus disertai dengan foto dan video agar orang lain tidak hanya dapat berimajinasi dengan informasi yang ada tetapi juga dapat melihat langsung lokasi dan pengalaman yang dialami oleh anggota yang membagikan informasi.

Kegembiraan membantu orang lain memiliki hubungan signifikan terhadap sikap terhadap knowledge sharing. Hasil ini sejalan dengan penelitian yang dilakukan Chang and Chuang (2011) yang mengatakan bahwa berinteraksi dengan cara saling berbagi informasi kepada orang lain didorong oleh sikap altruisme seseorang yang senang membantu orang lain.

Hubungan antara reputasi dengan sikap terhadap knowledge sharing memiliki nilai koefisien 0.293 dan nilai t-test 5.148. Nilai koefisien di atas 0.2 dapat diterima untuk mendukung konstruk yang ada. Hal ini berarti bahwa ada hubungan antara reputasi dengan sikap terhadap knowledge sharing. Reputasi yang dimiliki oleh penyebar informasi juga berpengaruh terhadap sikap mereka terhadap knowledge sharing karena semakin sering mereka memposting informasi di 
komunitas maka semakin terpercaya informasi mereka. Reputasi dapat didapatkan dengan keakuratan informasi yang ditulis, gaya bahasa penulisan dan keaktifan mereka di grup Backpacker Dunia. Semakin bagus reputasi penulis informasi, biasanya semakin akurat dan semakin sering mereka memposting tulisan karena mereka menyadari bahwa informasi yang mereka tulis ditunggu dan dibutuhkan oleh orang lain.

Abzari, Barzaki, and Abbasi (2011) awalnya hanya menyatakan bahwa reputasi mempengaruhi efektivitas dari knowledge sharing. Dalam penelitian ini, didapatkan hasil hubungan yang secara signifikan positif atas reputasi dan sikap terhadap knowledge sharing sehingga hasil penelitian ini semakin mendukung penelitian sebelumnya yang dilakukan oleh Prescott \& Louis (2010). Dalam rujukan tersebut menyatakan bahwa pertukaran dan penyebaran informasi tergantung dari reputasi yang dimiliki oleh individu yang bersangkutan dalam organisasi.

Hubungan antara sikap terhadap knowledge sharing dan tujuan melakukan knowledge sharing memiliki nilai koefisien 0.621 dengan nilai t-test 6.990. Signifikansi dapat dilihat pada perbandingan nilai $\mathrm{t}$ hitung dengan nilai t-tabel (t-hitung>ttabel), nilai t-tabel yang dibutuhkan pada penelitian ini adalah 2.05. Hal ini berarti bahwa sikap terhadap knowledge sharing memiliki hubungan positif dengan tujuan melakukan knowledge sharing. Para anggota grup Backpacker Dunia merasa senang membagikan pengalaman mereka karena mereka ingin orang lain yang membaca tulisan mereka juga merasakan hal yang sama dengan yang mereka rasakan. Berbagi informasi dan pengetahuan bagi mereka juga membantu orang lain untuk mengambil keputusan mengenai perjalanan yang akan mereka lakukan. Selain itu, berbagi pengetahuan dan pengalaman berarti saling bertukar informasi karena dalam setiap postingan pasti ada ada komentar yang dilontarkan oleh anggota grup yang lain.

Sikap terhadap knowledge sharing dengan tujuan melakukan knowledge sharing memiliki hubungan signifikan yang positif. Hal ini mendukung hasil penelitian dari Chow and Chan (2008), yang menjelaskan bahwa sikap berbagi informasi terhadap orang lain dipengaruhi oleh tujuan yang dimiliki oleh orang tersebut.

$\mathrm{R}^{2}$ adalah koefisien determinasi yang menunjukkan tingkat hubungan variable independent $(\mathrm{X})$ terhadap variable dependent $(Y)$. Koefisien determinasi menunjukkan seberapa besar pengaruh antara variable independent terhadap variable dependent. Nilai $R^{2}$ sebesar $0.19,0.33$ and 0.67 dapat dinyatakan sebagai nilai pengaruh yang rendah, sedang dan kuat (Hair et al., 2011).

Dalam penelitian ini tidak ada pengaruh $\left(\mathrm{R}^{2}\right)$ yang bernilai rendah, tetapi bernilai sedang dan tinggi. Di tabel 6 dalam penelitian ini $\mathrm{R}^{2}$ atau nilai koefisien korelasi sikap terhadap knowledge sharing adalah sebesar 0.804 atau dapat dibaca sebagai $80.4 \%$. Hal ini mengandung arti bahwa komitmen, kegembiraan membantu orang lain, dan reputasi memiliki pengaruh sebesar $80.4 \%$ dengan sikap terhadap knowledge sharing. Sesuai dengan penjelasan Hair et al. (2011), dalam 80.4\% adalah nilai pengaruh yang tinggi, sedangkan sisanya sebesar $19.6 \%$ dipengaruhi oleh variabel lain di luar model regresi ini.

Nilai $\mathrm{R}^{2}$ tujuan melakukan knowledge sharing adalah sebesar 0.385 . 
Hal ini berarti sikap terhadap knowledge sharing memiliki hubungan pengaruh sebesar $38.5 \%$ dengan tujuan melakukan knowledge sharing, atau dapat pula dikatakan bahwa pengaruh sikap terhadap knowledge sharing terhadap dengan tujuan melakukan knowledge sharing bernilai sedang. Sisa nilai $\mathrm{R}^{2}$ sebesar $61,5 \%$ dipengaruhi oleh variabel lain di luar model regresi pada penelitian ini. Besar pengaruh variabel lain yang didapat dari hasil pengurangan 100\% dengan jumlah besaran $\mathrm{R}^{2}$ biasa disebut error.

\section{SIMPULAN}

Penelitian ini menghasilkan model knowledge sharing pada pelancong yang belum pernah dilakukan sebelumnya. Hasilnya menunjukkan bahwa komitmen tidak memiliki hubungan dengan sikap terhadap knowledge sharing, sedangkan reputasi dan kegembiraan dalam membantu orang lain memiliki hubungan dengan sikap terhadap knowledge sharing. Selain itu, sikap terhadap knowledge sharing juga memiliki hubungan dengan tujuan melakukan knowledge sharing. Berbagi pengetahuan tidak hanya terjadi di organisasi atau institusi resmi, tetapi juga di komunitas pelancong. Pada komunitas ini, komitmen tidak berperan penting pada sikap anggota komunitas dalam melakukan knowledge sharing. Hal ini karena berbagi informasi bagi mereka bukanlah sebuah kewajiban, tetapi kegembiraan untuk berbagi dengan orang lain menjadikan anggota yang lain dapat tertarik mengikuti cerita perjalanan mereka. Selain itu, anggota yang tertarik pun dapat mengetahui lebih lanjut mengenai tempat yang mereka datangi sehingga para anggota yang senang berbagi informasi akan dianggap lebih terpercaya dalam memberikan informasi yang mereka butuhkan.

Berdasarkan hasil penelitian yang lalu, terutama penelitian mengenai grup traveling di media sosial, penelitian selanjutnya disarankan untuk menyempurnakan model penelitian mengenai knowledge sharing yang terjadi di dunia maya atau media sosial. Hal ini dapat dilakukan dengan menambahkan variabel baru yang belum pernah diteliti sebelumnya atau mengonfirmasi model yang telah ada dengan mencari sampel yang lebih besar. Selain itu, sampel penelitian dapat dikembangkan pada grup pariwisata lain yang sejenis agar didapatkan hasil yang lebih relevan untuk mengonfirmasi model yang telah ada sehingga dapat diketahui model knowledge sharing pada pelancong.

\section{DAFTAR PUSTAKA}

Abili, K., Thani, F. N., Mokhtarian, F., \& Rashidi, M. M. (2011). The role of effective factors on organizational knowledge sharing. In $\mathrm{Z}$. Bekirogullari (Ed.), International Conference on Education and Educational Psychology (ICEEPSY 2011) (Vol. 29, pp. 1701 - 1706). Turkey: Elsevier Procedia. https://doi.org/doi.org/10.1016/j.sb spro.2011.11.415

Abzari, M., Barzaki, A. S., \& Abbasi, R. (2011). Knowledge sharing behavior: organizational reputation or losing organizational power case study: employees of agricultural bank in Fars state. International Journal of Business and Social Science, 2(17), 144149. Retrieved from http://ijbssnet.com/journals/Vol_2_ No_17/20.pdf

Awang, Z. (2011). A handbook on SEM: 
structural equation modeling. Kelantan: Universiti Teknologi MARA.

Bohang, F. K. (2017). Pengguna aktif bulanan Facebook dekati angka 2 miliar. KOMPAS.com. Jakarta. Retrieved from https:/ / tekno.kompas.com/read/20 17/02/02/10130037/pengguna.aktif. bulanan.facebook.dekati.angka.2.mili ar

Chang, H. \& Chuang, S. (2011). Social capital and individual motivations on knowledge sharing: participant involvement as a moderator. Information $\mathcal{E}$ Management, 48(1), 918.

https://doi.org/doi.org/10.1016/j.i m.2010.11.001

Chen, W. \& Cheng, H. (2012). Factors affecting the knowledge sharing attitude of hotel service personnel. International Journal of Hospitality Management, 31(2), 468-476. https://doi.org/https://doi.org/10. 1016/j.ijhm.2011.07.005

Chow, W. \& Chan, L. (2008). Social network, social trust and shared goals in organizational knowledge sharing. Information $\mathcal{E}$ Management, 45(7), 458-465. https:/ / doi.org/doi:hthttps:/ / doi.or g/10.1016/j.im.2008.06.007

Dinther, M. V., Dochy, F., \& Segers, M. (2011). Factors affecting students' self-efficacy in higher education. Educational Research Review, 6(2), 95108.

https://doi.org/doi.org/10.1016/j.e durev.2010.10.003

Fauziyah, M. R., Damayani, N. A., \& Rohman, A. S. (2014). Perilaku knowledge sharing multi bahasa pada komunitas fakta bahasa. Jurnal Kajian Informasi \& Perpustakaan, 1(2),
87-102. Retrieved from http://jurnal.unpad.ac.id/jkip/articl e/view/11643

Fishbein, M. \& Ajzen, I. (2015). Belief, attitude, intention, and behavior: an introduction to theory and research. USA: Addison-Wesley. Retrieved from

ttps://www.researchgate.net/public ation/233897090_Belief_attitude_inte ntion_and_behaviour_An_introducti on_to_theory_and_research

Hair, J. F., Ringle, C. M., \& Sarstedt, M. (2011). PLS-SEM: indeed a silver bullet. Journal of Marketing Theory and Practice, 19(2), 139-152. Retrieved from

www.tandfonline.com/doi/pdf/10.2 753/MTP1069-6679190202

Henseler, J., Ringle, C. M., \& Sinkovics, R. R. (2009). The use of partial least squares path modeling in international marketing. In P. N. Sinkovics, R. R.; Ghauri (Ed.), Advances in International Marketing (pp. 277-319). Emerald JAI Press. Retrieved from https:// www.emeraldinsight.com/d oi/full/10.1108/S1474-

$7979 \% 25282009 \% 252$

Jeon, S., Kim, Y., \& Koh, J. (2011). An integrative model for knowledge sharing in communities-of-practice. Journal of Knowledge Management, 15(2), 251-269. Retrieved from http:/ / scihub.tw/https:/ / doi.org/10.1108/136 73271111119682

Lumbantobing, P. (2011). Manajemen knowledge sharing berbasis komunitas. Bandung: Knowledge Management Society Indonesia.

Ma, W.W.K. \& Chan, A. (2014). Knowledge sharing and social media: 
$\begin{array}{lcr}\text { altruism, } & \text { perceived online } \\ \text { attachment } & \text { motivation, and } \\ \text { perceived } & \text { online relationship } \\ \text { commitment. Computers in Human } \\ \text { Behavior, } & 39(10), & 51-58 .\end{array}$ https://doi.org/https://doi.org/10. 1016/j.chb.2014.06.015

Milne, P. (2007). Motivation, incentives and organisational culture. Journal of Knowledge Management, 11(6), 28-38. https://doi.org/https://doi.org/10. 1108/13673270710832145

Neininger, A., Lehmann-Willenbrock, N., Kauffeld, S., \& Henschel, A. (2010). Effects of team and organizational commitment-a longitudinal study. Journal of Vocational Behavior, 76(3), 567-579.

https://doi.org/doi.org/10.1016/j.jv b.2010.01.009

Prescott, E. \& Louis, H. (2010). How reputation affects knowledge sharing among colleagues. IT Sloan Management Review, 51(2), 79-81. Retrieved from https://www.researchgate.net/publi cation/272745489_How_reputation_a ffects_knowledge_sharing_among_co lleagues

Reza, J. I. (2017, April). Indonesia negara ke-4 dengan pengguna Facebook teraktif di dunia. https://www.liputan6.com. Jakarta. Retrieved from https:/ / www.liputan6.com/tekno/r ead/2926217/indonesia-negara-ke-4dengan-pengguna-facebook-teraktifdi-dunia

Saepudin, E., Rusmana, A., \& Budiono, A. (2016). Penciptaan pengetahuan tentang tanaman obat herbal dan tanaman obat keluarga. Jurnal Kajian Informasi \& Perpustakaan, 4(1), 95-106. Retrieved from http://jurnal.unpad.ac.id/jkip/articl e/view/11633

Scheible, A. C. F. \& Bastos, A. V. B. (2013). An examination of human resource management practices' influence on organizational commitment and entrenchment. Brazilian Administration Review, 10(1), 57-76. https:/ / doi.org/doi:http:/ / dx.doi.or g/10.1590/S1807-76922012005000011 Sholihin, M., \& Ratmono, D. (2013). Analisis SEM-PLS dengan WarpPLS 3.0. Yogyakarta: Penerbit Andi.

Singarimbun, M. \& Effendi, S. (2008). Metode penelitian survei. Jakarta: LP3ES.

Soto-Acosta, P. \& Merono-Cerdan, A. L. (2008). Analyzing e-business value creation from a resource-based perspective. International Journal of Information Management, 28(1), 49-60. https://doi.org/doi.org/10.1016/j.iji nfomgt.2007.05.001

Tan, C. N. \& Ramayah, T. (2014). The role of motivators in improving knowledge-sharing among academics. IR Information Research, 19(1), 606. Retrieved from http://www.informationr.net/ir/191/paper606.html\#.Wy-BGtIzbMw

Tsai, M., Chen, K., \& Chien, J. (2012). The factors impact of knowledge sharing intentions: the theory of reasoned action perspective. Quality $\mathcal{E}$ Quantity, 46(5), 1479-1491. Retrieved from

https:/ /link.springer.com/article/10 .1007/s11135-011-9462-9

Umaedah, U. (2015). Komunitaskomunitas traveling di Facebook yang membuatmu serasa memiliki keluarga baru. Retrieved from https:/ / phinemo.com/komunitaskomunitas-traveling-di-facebook- 
yang-membuatmu-serasa-memilikikeluarga-baru/

Yusuf, O. (2016). Jumlah pengguna Facebook di Indonesia terus bertambah. KOMPAS.com. Jakarta. Retrieved from

https://tekno.kompas.com/read/2016/1 0/20/17062397/jumlah.pengguna.facebo ok.di.indonesia.terus.bertambah Zacoeb, A. (2009). Metode penelitian: populasi dan sampel. Retrieved February 10, 2018, from http:/ / zacoeb.lecture.ub.ac.id/files/ 2015/02/MG4-Populasi-danSampel.pdf 


\section{DAFTAR TABEL}

Tabel 1

Variabel dan indikator penelitian

\begin{tabular}{|c|c|c|}
\hline Variabel & Singkatan & Indikator \\
\hline \multirow[t]{3}{*}{ Komitmen } & $\mathrm{KO}$ & Kepedulian terhadap keberlangsungan grup \\
\hline & & Berbagi informasi mengenai grup kepada orang lain \\
\hline & & Kebanggaan menjadi anggota grup \\
\hline \multirow{5}{*}{$\begin{array}{l}\text { Kegembiraan mem- } \\
\text { bantu orang lain } \\
\text { Reputasi }\end{array}$} & KG & Kenikmatan berbagi informasi pada grup \\
\hline & & Kegembiraan sewaktu berbagi informasi pada grup \\
\hline & $\mathrm{RE}$ & $\begin{array}{l}\text { Penghargaan oleh orang lain sewaktu berbagi informasi pada } \\
\text { grup }\end{array}$ \\
\hline & & Peningkatan popularitas setelah berbagi informasi pada grup \\
\hline & & Peningkatan reputasi setelah berbagi informasi pada grup \\
\hline Sikap terhadap & SKS & Kelancaran proses berbagi informasi pada grup \\
\hline knowledge sharing & & Pengalaman berbagi informasi pada grup \\
\hline Tujuan melakukan & TKS & Proses berbagi pengalaman perjalanan pada grup \\
\hline knowledge sharing & & \\
\hline
\end{tabular}

Sumber: Olahan penulis, 2017 
Tabel 2

Loading factor

\begin{tabular}{llllll}
\hline & KO & KG & RE & SKS & TKS \\
\hline KO1 & 0.817 & & & & \\
KO2 & 0.729 & & & & \\
KO3 & 0.738 & & & & \\
KO4 & 0.738 & & & & \\
KO5 & 0.700 & & & & \\
KG1 & & 0.749 & & & \\
KG2 & & 0.834 & & & \\
KG3 & & 0.895 & & & \\
KG4 & & 0.917 & & & \\
RE1 & & & 0.795 & & \\
RE2 & & & 0.887 & & \\
RE3 & & & 0.820 & & \\
RE4 & & & 0.694 & & \\
SKS1 & & & & 0.82 & \\
SKS2 & & & & 0.891 & \\
SKS3 & & & & 0.843 & \\
SKS4 & & & & 0.856 & \\
TKS2 & & & & & 0.836 \\
TKS3 & & & & & 0.714 \\
TKS4 & & & & & 0.851 \\
TKS5 & & & & & \\
\hline
\end{tabular}

Sumber: Hasil penelitian, 2017 
Tabel 6

Hasil pengukuran hipotesis pada model

\begin{tabular}{lllll}
\hline Hipotesis & Causal path & Path coefficient & Nilai t-hitung & Signifikansi \\
\hline $\mathrm{H}_{1}$ & $\begin{array}{l}\text { Komitmen } \rightarrow \text { sikap } \\
\text { terhadap knowledge } \\
\text { sharing }\end{array}$ & 0.093 & 1.041 & $\begin{array}{l}\text { Tidak } \\
\text { signifikan }\end{array}$ \\
$\mathrm{H}_{2}$ & $\begin{array}{l}\text { Kegembiraan mem- } \\
\text { bantu orang lain } \rightarrow \\
\text { Sikap terhadap } \\
\text { knowledge sharing } \\
\text { Reputasi } \rightarrow \text { sikap } \\
\text { terhadap knowledge } \\
\text { sharing } \\
\text { Sikap terhadap } \\
\text { knowledge sharing } \rightarrow \\
\text { tujuan melakukan } \\
\text { knowledge sharing }\end{array}$ & 0.714 & 9.288 & Signifikan \\
$\mathrm{H}_{3} \quad 0.621$ & & & \\
& & & & \\
$\mathrm{H}_{4} \quad$ & 6.148 & Signifikan \\
& & & \\
\end{tabular}

Sumber: Hasil penelitian, 2017 